\title{
When the World Helps Teach Your Class: Using Wikipedia to Teach Controversial Issues
}

\author{
Mark K. Cassell, Kent State University
}

\section{ABSTRACT Assigning students to draft and publish a Wikipedia contribution is no longer} a novelty. The pedagogical benefits from assigning a Wikipedia article vary depending on discipline, lesson plan, and how it is incorporated into the class. This research considers how a Wikipedia assignment can effectively overcome common challenges in teaching controversial topics including peer relations, teacher-student power dynamics, and (mis) perceptions of "the other."

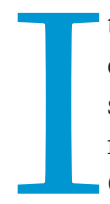
$\mathrm{t}$ is a problem almost everyone who teaches political science confronts at some point: how to effectively teach a controversial topic. Same-sex marriage, gun control, race, reproductive rights, even the presidential election (Burkstrand-Reid, Karen and Briggs 2011): the topics are charged with emotion. Students arrive to class with entrenched beliefs that undermine efforts to foster critical thinking. Opposing and contradictory viewpoints are easily interpreted as personal attacks, degenerating into disruption, withdrawal, or both. Whereas most Americans are entertained by controversy and conflict in sports and reality television, they are repelled by disputes about politics, policy, and governance (Hess 2004; Hibbing and Theiss-Morse 2007). This article explores how Wikipedia, the web-based encyclopedia, provides a useful tool to overcome some of the challenges of teaching controversial topics. The article draws on the author's recent experience teaching an upper-division writing-intensive seminar in political science titled "The Politics of Inequality." A major course assignment (worth almost half the grade) was the publication of a Wikipedia article on a topic related to inequality.

\section{WHY TEACH ABOUT CONTROVERSIAL TOPICS IN POLITICAL SCIENCE?}

Whether controversial topics should be taught is itself controversial (Hess 2004). Social-education research suggests at least four reasons to engage students with controversial topics in class.

First, classrooms are ideal spaces to discuss controversial issues because they typically contain greater ideological diversity than expected in a family, religious institution, or civil-society associations. The variation in perspectives creates conditions

Mark K. Cassell is professor of political science at Kent State University. He can be reached at mcassell@kent.edu. for rational deliberations of competing conceptions of positive outcomes in life, good society, government, and policy (Gutmann 1999). Second, discussions of controversial topics enhance democratic thinking (Hess 2004). Research has found that discussions of contested policies correlate positively with developing more tolerant attitudes (Avery 2002; Evans and Saxe 2007; Hahn 1998). Third, when students experience classrooms as venues to investigate controversial issues, civic knowledge and political engagement increase (Hess 2002; Newman 1989; Torney-Purta, Lehmann, and Oswald 2001). Fourth, teaching controversial topics improves critical thinking and interpersonal skills. Listening and engaging with peers who think differently are important interpersonal skills enhanced by raising controversial topics and issues in the classroom (Johnson and Johnson 2009).

\section{PEDAGOGICAL CHALLENGES OF TEACHING CONTROVERSIAL TOPICS}

Deciding whether to teach a controversial topic depends on various factors, including whether the topic is sufficiently controversial, an instructor's personal comfort with the topic, and concerns about community disapproval (Hess 2002, 36). There also are pedagogical hurdles to teaching controversial topics; three challenges stand out. The first is peer relations. Burkstrand-Reid, Carbone, and Hendricks $(\mathbf{2 0 1 1}, 4)$ argued "the most feared entity in the classroom is not the professor or the test, but the classmate." Peer relations determine how students engage with a controversial topic and whether they become defensive, are open to examining assumptions behind a topic, or simply shut down. Indeed, Lusk and Weinberg (1994) found that students sometimes opt out of a discussion altogether rather than risk jeopardizing relationships outside of class.

A second challenge encompasses the power relations between student and teacher. Students typically arrive at college with "years of training in listening passively and answering brief 
questions from the teachers with correct answers" (Innes 2007, 13). Yet, for productive exchanges on controversial topics, students must believe that they will not be corrected or penalized because they disagree with the instructor or their classmates. Faculty, therefore, must develop techniques to overcome reluctance among students caused by perceived power differences.

The third challenge in teaching controversial topics is developing techniques to overcome stereotypes. Students experience our culture in ways that encourage them to reduce information into simplistic dichotomies (Hedley and Markowitz 2001). When social realities are reduced to simple dichotomies, students' understanding is reduced to "us versus them" distinctions, which further undermines learning. The challenge is to help students appreciate historical, political, and social processes that create and perpetuate stereotypes. to develop the very skills and perspectives that help them outside of the classroom. A fourth problem with traditional approaches is that regardless of the setting or assignment, there are always students who withdraw from the conversation. Fifth, regardless of how student-centered an activity is or how much I solicit their views, I-the instructor-often talk and lecture too much.

Thus, in thinking about an alternative to traditional approaches to teaching controversial topics, I sought an approach that would address areas where traditional approaches fell short.

\section{WIKIPEDIA AS AN APPROACH}

Although academics view Wikipedia with skepticism, a growing scholarly literature illustrates the pedagogical value of publishing assignments (Kennedy et al. 2015; Konieczny 2016).

\section{Teachers approach controversial topics in one of the following four ways (Hess 2004): (1) denial, teaching as if there were no controversy; (2) privilege, teaching from a particular perspective; (3) avoidance, avoiding the controversial issue altogether; or (4) balance, teaching the topic as a controversial issue with a focus on differing perspectives.}

\section{WHERE TRADITIONAL APPROACHES TO TEACHING CONTROVERSIAL ISSUES FALL SHORT}

Teachers approach controversial topics in one of the following four ways (Hess 2004): (1) denial, teaching as if there were no controversy; (2) privilege, teaching from a particular perspective; (3) avoidance, avoiding the controversial issue altogether; or (4) balance, teaching the topic as a controversial issue with a focus on differing perspectives. In my teaching, I use a traditional and balanced approach. I typically assign readings from diverse theoretical and substantive perspectives accompanied by a mix of lectures and experiential learning-case-method, classroom debate, student presentation, group-led discussion, role-playing, and so on. Although learning objectives vary across courses, I have two goals when I teach a controversial topic. The first is that students who complete the class have an understanding of the complexities of controversial topics, including different perspectives about what is at stake. The second is to create an intellectual space in which students engage controversial topics by expressing and debating different perspectives.

Although this traditional approach works most of the time, it can fall short with controversial topics. First, students tend to be good at articulating their opinions but struggle to appreciate their biases. Writing a balanced or neutral paragraph, for example, is a constant challenge because students often are blind to their own biases. A related problem is that students often talk at each other rather than listen to other points of view. Most faculty seek a robust classroom discussion and broad participation. However, the discussion format, in which students must respond quickly, often comes at the cost of reflection and appreciation of another's point of view.

A third problem in a traditional course is that students often fail to see that their work has relevance beyond the class or their grade. The disconnect between the classroom and the outside world is particularly problematic when teaching about controversies because a point of the exercise is for students
Kennedy et al. (2015, 382), for example, described how introductory courses in comparative politics and elections can be improved by incorporating the editing of a Wikipedia article into the lesson plan. Although not a panacea, Kennedy and his colleagues found that a Wikipedia assignment can be a useful active-learning tool to overcome challenges with teaching a controversial topic.

Fesakis and Zoumpatianou (2012) described the learning objectives fostered by a Wikipedia assignment, including the ability to (1) write in a fact-based, neutral tone that is clear and concise (Grauerholz 1999); (2) navigate the media landscape and differentiate good from unreliable sources (Tapscott and Williams 2007); (3) recognize when information is presented in a non-biased, accurate way (Reilly 2010); (4) develop criticalthinking skills (Patch 2010); and (5) communicate effectively and respectfully in an online environment (Bruns and Humphreys 2005).

Research also has found that the novelty of editing or contributing to Wikipedia makes it a fun, enjoyable assignment (Callis et al. 2009; Konieczny 2012). As Konieczny (2012) noted, "[t]he Wikipedia assignment...has a potential to be more enjoyable than most other traditional assignments, and some studies of student motivations report high student assessments." The motivation derives from the fact that students see their writing having a visible impact on the world (Konieczny 2016, 1528).

Given the expectations in the teaching literature on Wikipedia, I opted to incorporate a Wikipedia assignment into a senior writing seminar. The following discussion describes the course, the assignment, and the results.

\section{TEACHING ABOUT INEQUALITY USING WIKIPEDIA}

Few topics are as controversial as inequality. "What Happened to All Men Are Created Equal?: The Politics of Inequality in the United States" is an upper-division writing-intensive course ${ }^{1}$ in political science built around five topics. The class began by 
exploring diverse theoretical positions on whether inequality is a public problem. We discussed public-opinion research. The discussion then turned to the current state of inequality for the overall population, by gender, and by race. In addition to exploring different measures of inequality, we examined inequality in Ohio (where my university is located) and cross nationally. A third section discussed causes cited for increasing inequality including
Once their drafts were on the main website, students conducted another round of peer reviews. As with previous drafts, students commented on two other students' Wikipedia sites. Also, they were surprised when Wikipedia editors and automatic editing systems flagged articles and, in some cases, removed them because the articles failed to comply with one of Wikipedia's policies.4 In the final weeks of the semester, students revised their

Once their drafts were on the main website, students conducted another round of peer reviews. As with previous drafts, students commented on two other students' Wikipedia sites. Also, they were surprised when Wikipedia editors and automatic editing systems flagged articles and, in some cases, removed them because the articles failed to comply with one of Wikipedia's policies.

globalization, declines in organized labor, technological changes, and public policies. The effects of inequality on health, well-being, and participation in the political process were discussed in a fourth section. A fifth section examined several policy solutions to address inequality.

Students were required to complete a variety of writing assignments: (1) four short reaction papers; (2) a medium-length (i.e., 8-10 pages) research paper on a topic related to inequality; and (3) a Wikipedia article on a topic related to their research paper. The syllabus and supporting materials used by the students to develop their assignment are in appendix 1.

Based on the research of other scholars (Kennedy et al. 2015), the Wikipedia assignment was organized into a series of short tasks and quick "how-to" lectures integrated throughout the course. Class time was set aside to introduce students to Wikipedia's content, rules and norms, and-most important-the technical knowledge needed to complete the assignment. The first two weeks were dedicated to introducing Wikipedia editing techniques, Talk Pages, ${ }^{2}$ and criteria to assess what defines a good or bad article. At the beginning of the semester, students registered an account with Wikipedia, practiced using Talk Pages, and completed an online training course on how to use Wikipedia. In addition to providing technical knowledge, the training addressed norms and rules that govern the editing process.

After students were familiar with Wikipedia, attention focused on selecting topics. In addition to one-on-one meetings, I found it helpful to spend a half-hour of class time brainstorming ideas, demonstrating what a "stub" 3 is, and exploring how to search for a topic. To practice editing techniques, students were required in the third week to add one or two sentences of new information to an existing Wikipedia article, supported by a citation to an appropriate source.

By the sixth week, students were required to post the first draft of their Wikipedia article in their "Sandbox," a space to experiment with different versions of an edit. Drafts consisted of three to four paragraphs and followed Wikipedia's article format (Wikipedia Media 2014). Once their draft was posted, students were required to provide feedback on two other student drafts in the Talk Pages linked to the Sandbox. Students then incorporated peer reviews and my comments into rewrites of their draft articles. By the eighth week, drafts were moved from the Sandbox to Wikipedia's main website.
Wikipedia contributions in response to new information they collected, comments from editors, and other Wikipedia articles. While revising their pieces, students also completed an 8- to 10-page research paper that supplemented their Wikipedia contribution.

In the final week of class, students gave brief presentations on their Wikipedia contribution and the challenges of the assignment. The range of articles included (1) health care disparities in Cuyahoga County; (2) inequality in stock-market ownership; (3) the impact of Ohio voting rules on racial inequality; and (4) inequality in Germany (see appendix 2 for sample articles). Students also drafted a brief reflective essay on what they had learned and what they thought worked and did not work.

The Wiki Education Foundation provided two resources that proved invaluable. First was an online Dashboard run by Wikimedia Foundation (see appendix 3). Once registered with Wikipedia, students signed on to a course Dashboard. The Dashboard enables the instructor to see whether students complete the online training and tasks. It also facilitates the peer-review system by enabling students to click to another student's edits. The Dashboard tracked the progress of each of the 27 students.

A second resource was the assistance of an experienced Wikipedia Content Expert who works for the Wiki Education Foundation. The assistant provided technical support, monitored student contributions, and answered their questions. Knowing someone was available with technical expertise increased the students' confidence that they could complete the project.

In short, the Wikipedia assignment was structured around small tasks and incremental steps. Rather than complete a polished research paper after several drafts, the assignment sought to help students complete an acceptable foundation for an article. Once online, contributions developed organically with input from peers, the instructor, and external editors.

\section{EVALUATION OF THE WIKIPEDIA ASSIGNMENT}

Several data sources paint a picture of the impact of Wikipedia assignments on learning in general and controversial topics in particular. First, students completed an anonymous survey that asked specific questions about the assignment. The survey was administered in class and included a mix of multiple-choice and open-ended questions intended to measure perceptions of the 
assignment, difficulty of specific parts of the assignment, and which elements worked or failed. A second evaluation survey given by the university asked a set of generic questions about the quality of the course and the teaching.

Third, a qualitative data source is the reflective essay written by each student. These essays provided the best account of what the students believed they learned as well as the assignment strengths and weaknesses. The essays were coded twice using the qualitative software program NVivo: first by me and then by a research assistant. A final source of data is the notes I took throughout the semester following classes or one-on-one meetings with students concerning challenges, strengths, and impact of the assignment. The notes provided a check on my memory.

\section{HOW DID THE ASSIGNMENT EASE THE CHALLENGES OF TEACHING CONTROVERSIAL TOPICS?}

Given the topics in this class-racial and gender inequality, organized labor, the minimum wage-it is not surprising that class sessions often generated heated and intense discussions. The Wikipedia assignment mediated several challenges that typically occur when teaching about controversies.

Being required to comment on draft edits of others in a semiprivate way reduced anxiety that comes from talking publicly about a controversy in class. Semi-private means that although anyone could view a peer's feedback, comments were written
The power relationship between student and instructor also can impede learning: students (and some faculty) are reluctant to challenge the "teacher as the disseminator of knowledge" metaphor. The Wikipedia assignment disrupted that metaphor in several ways. First, it was clear at the outset that I, the instructor, was not going to be the disseminator of knowledge regarding editing Wikipedia. Students understood that I often had less experience editing websites than they did. Working with students one-on-one fostered a sense of mutual learning and teaching.

Second, in a typical research paper, students perceive the primary audience to be the instructor. This can reinforce the power relationship between student and faculty that impedes learning. In the Wikipedia assignment, the audience is the instructor, the class, and the world. Students clearly understood that they were writing for others-their parents, their friends, and the public. Three quarters of the class stated that they shared their Wikipedia contribution with others outside of class including friends, family, and-in one case"as many people as I could." Three quarters of the class answered "Yes" to the question: "Does the fact that your Wiki article lives on after the class ends change the way you approached the assignment?"

Feedback and edits of others (not the instructor) coupled with a requirement to search for other Wikipedia articles on the same topic eroded the impression that the instructor was the only legitimate source of knowledge. Seeing their work published, expanded, and cited by other authors enforced a view that they-the studentscould be the legitimate source of knowledge and information.

\section{Seeing their work published, expanded, and cited by other authors enforced a view that they-the students-could be the legitimate source of knowledge and information.}

on Talk Pages connected to a Sandbox and were viewed primarily by the commenter and the author. There were two rounds of peer reviews-once in the draft phase and again after the document had been moved to Wikipedia's main site. Several students wished there had been more peer-review opportunities. They cited peer reviews most often as the part of the assignment that worked best. One student commented, "Knowing that by creating an article I would be inviting others to add to and criticize my work, I was more mindful about the quality and organization of my article."

The peer reviews created a class space in which students felt comfortable expressing views. Comments were made electronically without seeing reactions from the full class or even from the student who wrote the piece. Wikipedia is built on peer reviews and the edits and additions of others. The fact that students observed this process firsthand and were required to conduct at least four peer reviews raised the class comfort level and fostered a peer-review culture in class. Peer reviews also enabled students to see others' progress (or lack thereof)-which also helped to break down barriers. One student acknowledged that she was (pleasantly) surprised to see how much another student was struggling with the same technical issues that she was. Finally, an interesting dynamic occurred at least twice during the class when a Wikipedia editor criticized a student's edit. In response to the editor's comment, other students in class came to their colleague's defense, expressed sympathy, and offered solutions to the editor's concerns.
A third challenge with teaching controversial topics is helping students understand stereotypes. These can be difficult conversations, particularly in discussions of gender and racial inequality. The Wikipedia assignment included features that mediated the problem. The most important element was Wikipedia's insistence that all contributions (1) be written from a neutral point of view; (2) not be original but rely on the work of others; and (3) be verifiable with peer-reviewed citations. Although most students felt strongly about inequality-whether it was a public or private problem, for example-Wikipedia's policies prohibited students from simply expressing their opinions. Moreover, Wikipedia's policies (and notably not the instructor's) forced students to consider the views and perspectives of others, which was one of the most difficult challenges. Indeed, "writing in a neutral way" was the second most-often-mentioned challenge of the course.

Wikipedia's rigid structure and format created a space to explore assumptions and social context. Wikipedia's automatic editors, classroom peers, and external editors were quick to edit students who simply wrote opinions, used stereotypes, or made unsubstantiated claims. Students often complained about the editing and comments to me and to the Wikipedia Foundation assistant helping with the class. Responding to editors' concerns forced students to confront their assumptions and biases. This led to healthy discussions in class and on the Talk Pages.

In short, the Wikipedia assignment mediated challenges associated with teaching a controversial subject. Clearly, the assignment was by no means a perfect remedy. From the students' 
perspective, a number of elements worked well and other elements did not work at all (tables 1 and 2).

When asked to identify the greatest challenge with the assignment, students most-often mentioned formatting and technical issues. Despite the training and the Dashboard, it was difficult to navigate Wikipedia's clumsy interface and formatting. The Wikipedia Foundation assistant was helpful; however, what often seemed straightforward in the training video turned out to be more complicated.

Nevertheless, the majority of students (i.e., $85 \%$ ) found the Wikipedia assignment useful and praised the long-term nature of the project as a positive feature. The fact that contributions lived on beyond the scope of the class enhanced their feeling of ownership for the project.

\section{REFLECTIONS ON THE ASSIGNMENT: WHAT WOULD I DO DIFFERENTLY?}

Incorporating a Wikipedia assignment into a lesson plan is not for the faint of heart. It is an active-learning exercise that requires a significant investment of time and planning. It also requires students to learn a new technology and writing style. For the most part, they were more than willing to go along for the ride. Indeed, although they were surprised by the assignment, their feedback and performance suggest that the learning objectives were met in most cases. That said, there are several things I would consider doing differently.

First, as with any new assignment, there is a learning curve in determining technology, time management, and ideal teaching process. The Wiki Education Foundation's resources, including the Dashboard, helped immensely. Online resources include a tutorial that introduces students to Wikipedia editing (http:// en.wikipedia.org/wiki/Wikipedia:Tutorial) and to creating a user page (http://en.wikipedia.org/wiki/Wikipedia:Userpages).

A department might consider investing in training a person-a departmental Wikipedian-to help faculty tailor an assignment to course learning objectives and student demographics.

Second, I would consider two variations in the future. The first is a group-project format. Rather than have each student publish an article, which requires significant one-on-one teaching, a more common approach for a larger class is for small groups to work together on an article. A second variation is to assign an entire class to draft or improve a Wikipedia article. Students can work in groups or individually on different sections. With group- or singleclass projects, they would complete smaller assignments individually but work collaboratively to develop ideas, conduct research, draft articles, provide feedback, and assist with rewrites. A common problem among group projects is that some students fail to pull their weight. However, the Wikipedia Dashboard remedies this by enabling the instructor to monitor and evaluate each group member's contribution.

Third, a feature of the Wikipedia assignment-and often writing-intensive courses in general-is that students are asked to synthesize existing knowledge rather than develop new knowledge or their own views. The reflective essay asks students to reflect on the process of drafting a Wikipedia article. However, Massengill (2011) suggested going even further to ask students to take the Wikipedia article they wrote and draft an essay that applies their article to something they 
observed in their own life or the media. Alternatively, students could be encouraged to use Wikipedia's discussion-page tabs to formulate their own views on the article they drafted. Pollard (2008) noted that the Wikipedia discussion space gives students a place to discuss how an article was constructed and to defend edits they made.

Fourth, although students were familiar with Wikipedia, most were surprised by the drafting and editing process. They stated that they were shocked by the comments and reviews of editors and peers. One way to address the lack of familiarity with Wikipedia standards is to involve students in a community-review project (Konieczny 2012). Wikipedia has several, including the following:

- Did You Know (DYK) (http://en.wikipedia.org/wiki/Wikipedia: Did_you_know) showcases new or expanded articles through informal review.

- Good Article Nominations (GAN) (http://en.wikipedia.org/ wiki/Wikipedia:Good_article_nominations) enables readers to review an article against good-article criteria. If selected, the article receives a small green icon at the top, indicating that it has been deemed good by a reviewer.

- Peer Review (PA) (http://en.wikipedia.org/wiki/Wikipedia: Peer_review) is a way to receive ideas and feedback from other editors. An article is nominated by any user and appears on the list of all peer reviews. Other users can comment on the review.

- Featured Article (FA) http://en.wikipedia.org/wiki/Wikipedia: Featured_article_candidates) showcases the best work in Wikipedia. The process is similar to GAN.

These community-review projects provide an easy, low-stress way for students to learn about quality, convey more information about what is expected, and generate community involvement in their project.

In summary, there is compelling evidence that teaching about controversial topics in social science classes benefits students by fostering rational deliberative discussion, critical thinking, and democratic norms. At the same time, controversial topics pose a particular set of pedagogical challenges that can undermine the effectiveness of teaching about a difficult topic. I continue to use various traditional techniques to overcome those challenges. My experience in using a Wikipedia assignment in conjunction with more traditional techniques yielded generally positive results.

When I first considered incorporating a Wikipedia assignment into my course, I expected a learning curve. What I did not anticipate is how the assignment made discussions and learning about inequality easier. The assignment reduced the anxieties often caused by class-peer relations. It provided a vehicle for challenging the traditional student-instructor power relationship that can interfere with learning. Finally, Wikipedia's rigid structure and format forced students to confront assumptions that create our (mis)perceptions and stereotypes.

\section{SUPPLEMENTARY MATERIAL}

To view supplementary material for this article, please visit https://doi.org/10.1017/S1049096517002293

\section{NOTES}

1. A writing-intensive course requires a substantial amount of writing and at least one writing assignment in which there is an opportunity for guided revision (http://catalog-archive.kent.edu/archive/catalog/2015/info/courseinformation/ wic.html).
2. A Talk Page is a comment or discussion page linked to every Wikipedia article. Editors use Talk Pages to discuss improvements or debate content. It is the main way in which feedback is delivered.

3. A stub is a short article in Wikipedia in need of expansion. Stubs are good places to start; find lists of stubs in Wikipedia by topic.

4. Five policies are the cornerstone of Wikipedia: (1) content must be free; (2) sources must be reliable; (3) point of view must be neutral; (4) the concept or contribution must be of some note; and (5) everyone who edits should assume good faith when interacting with others (Wikipedia Foundation n.d., 3).

5. Students wrote essays in which they were asked to reflect on three topics: (1) what aspects of the assignment they felt were successful; (2) what challenges they confronted; and (3) what they had learned in the course. A total of 20 students completed the reflection essay. Each essay was "interviewed" by coding the responses using NVivo. Tables 1 and 2 summarize the responses and the number of times they were mentioned by different students. In addition, a sample quote for each topic that best captures the students' sentiment is included.

\section{REFERENCES}

Avery, Patricia G. 2002. "Political Tolerance, Democracy, and Adolescents: Contexts, Curricula, Assessments." In Education for Democracy: Contexts, Curricula, Assessments, ed. Walter C. Parker, 113-30. Greenwich, CT: Information Age Publishing.

Bruns, Axel, and Sal Humphreys. 2005. "Wikis in Teaching and Assessment." In Proceedings of the 2005 International Symposium on Wikis, WikiSym 05: 25-32. New York: Association for Computing Machinery.

Burkstrand-Reid, Beth, June Carbone, and Jennifer S. Hendricks. 2011. "Teaching Controversial Topics." Family Court Review 49 (4): 678-84.

Callis, Kristine, Lindsey R. Christ, Julian Resasco, David W. Armitage, Jeremy D. Ash, Timothy T. Caughlin, et al. 2009. "Improving Wikipedia: Educational Opportunity and Professional Responsibility." Trends in Ecology \& Evolution 24 (4): 177-9.

Cowan, Paula, and Henry Maitles. 2012. Teaching Controversial Issues in the Classroom: Key Issues and Debates. New York: Continuum International Publishing.

Evans, Ronald W., and David W. Saxe. 2007. Handbook on Teaching Social Issues: NCSS Bulletin No. 93. Washington, DC: National Council for the Social Studies.

Fesakis, Georgios, and M. Zoumpatianou. 2012. "Wikipedia Uses in Learning Design: A Literature Review." Themes in Science and Technology Education 5 (1-2): 97-106.

Grauerholz, Liz. 1999. "Creating and Teaching Writing-Intensive Courses.” Teaching Sociology 27 (4): 310.

Gutmann, Amy. 1999. Democratic Education. Princeton, NJ: Princeton University Press.

Hahn, Carole. 1998. Becoming Political: Comparative Perspectives on Citizenship Education. Albany: State University of New York Press.

Hedley, Mark, and Linda Markowitz. 2001. "Avoiding Moral Dichotomies: Teaching Controversial Topics to Resistant Students." Teaching Sociology 29 (2): 195-208.

Hess, Diana E. 2002. "Discussing Controversial Public Issues in Secondary Social Studies Classrooms: Learning from Skilled Teachers." Theory \& Research in Social Education 30 (1): 10-41.

- 2004. "Controversies about Controversial Issues in Democratic Education." Political Science \& Politics 37 (2): 257-61.

Hibbing, John R., and Elizabeth Theiss-Morse. 2007. Stealth Democracy: Americans Beliefs about How Government Should Work. Cambridge: Cambridge University Press.

Innes, Robert B. 2007. "Dialogic Communication in Collaborative ProblemSolving Groups.” International Journal for the Scholarship of Teaching and Learning 1 (1): 1-18.

Johnson, David W., and Frank P. Johnson. 2009. Joining Together: Group Theory and Group Skills. Boston: Pearson.

Karen, Mason A., and Lisa T. Briggs. 2011. "Myths and Moral Panics: An ActiveLearning Approach to Controversial Topics." Transformative Dialogues: Teaching $\mathcal{E}$ Learning Journal 5 (1): 1-14

Kennedy, Ryan, Eric Forbush, Brian Keegan, and David Lazer. 2015. “Turning Introductory Comparative Politics and Elections Courses into Social Science Research Communities Using Wikipedia: Improving Both Teaching and Research.” PS: Political Science \& Politics 48 (2): 378-84.

Konieczny, Piotr. 2012. "Wikis and Wikipedia as a Teaching Tool: Five Years Later." First Monday 17 (9), doi: 10.5210/fm.voio.3583.

. 2016. "Teaching with Wikipedia in a 21st-Century Classroom: Perceptions of Wikipedia and its Educational Benefits." Journal of the Association for Information Science and Technology 67 (7): 1523-34.

Lusk, Amy B., and Adam S. Weinberg. 1994. "Discussing Controversial Topics in the Classroom: Creating a Context for Learning." Teaching Sociology 22 (4): 301. 
Massengill, Rebekah Peeples. 2011. "Sociological Writing as Higher-Level Thinking: Assignments That Cultivate the Sociological Imagination." Teaching Sociology 39: 371-8.

Newman, Frank M. 1989. "Reflective Civic Participation.” Social Education 53 (6): 357-61.

Patch, Paula. 2010. "Meeting Student Writers Where They Are: Using Wikipedia to Teach Responsible Scholarship." Teaching English in the Two-Year College $37(3): 278-85$.

Pollard, Elizabeth Ann. 2008. "Raising the Stakes: Writing about Witchcraft on Wikipedia." History Teacher 42 (1): 9-24.

Reilly, Colleen A. 2010. "Teaching Wikipedia as a Mirrored Technology." First Monday 16 (1): http://ojphi.org/ojs/index.php/fm/article/view/2824/2746.
Tapscott, Don, and Anthony D. Williams. 2007. Macrowikinomics: Rebooting Business and the World. Toronto: Penguin Canada.

Torney-Purta, Judith, Rainer Lehmann, and Hans Oswald. 2001. Citizenship and Education in Twenty-Eight Countries: Civic Knowledge and Engagement at Age Fourteen. Amsterdam: International Association for the Evaluation of Educational Achievement.

Wikipedia Media. 2014. Case Studies on How to Use Wikipedia as a Teaching Tool in Higher-Education Classrooms as Part of the Wiki Education Foundation's Classroom Program. Available at https://commons.wikimedia.org/wiki/File:Case_Studies, How_instructors_are_teaching_with_Wikipedia_\%28Wiki_Education_ Foundation\%29.pdf.

Wikipedia: Statistics. n.d. Available at https://en.wikipedia.org/wiki/Wikipedia Statistics. Accessed March 14, 2016 